\title{
Jotas en tittels het betekenis - die krities-eksegetiese en teologiese bydrae van Andries Breytenbach as Bybelvertaler
}

Author:

Ananda B. Geyser-Fouché ${ }^{1}$

Affiliation:

${ }^{1}$ Department of Old

Testament Studies,

University of Pretoria,

South Africa

Note:

The article is a

reworked version of a paper presented at a

commemoration ceremony by the Department of Old Testament Studies, University of Pretoria and the South African Bible Society in honour of two emeritus professors of the Department of Old Testament Studies for their contributions to Bible translation. This contribution focuses on Prof. Dr Andries P.B. Breytenbach's role, especially in the translation of the Old Testament into isiNdebele. This article is published as part of the tribute towards an alumnus of the Faculty of Theology, Professor James Alfred Loader, who retires in 2013 as Old Testament scholar from the University of Vienna.

\section{Correspondence to:} Ananda Geyser-Fouché

Email:

ananda.geyser-fouche@

up.ac.za

Postal address:

Private Bag X20, Hatfield 0028, Pretoria, South Africa

\section{Dates:}

Received: 15 Mar. 2013

Accepted: 08 Apr. 2013

Published: 29 May 2013

Read online:
Jots and tittles have meaning: The critical exegetical and theological contribution of Andries Breytenbach as Bible translator. The article is a reworked version of a paper presented at a commemoration ceremony in honour of the retired Reformed exegetes of the Department of Old Testament Studies of the Faculty of Theology at the University of Pretoria who have contributed immensely to translation projects of the South African Bible Society. In this article, the author focuses on the theological and exegetical relevance of Professor A.P.B. Breytenbach. The article shows Breytenbach's critical presuppositions in hermeneutics, especially his contribution towards the understanding of diversity in the message of the Old Testament and the 'second naiveté' which constitutes a critical lens through which the Old Testament should be interpreted by the Christian faith community.

\section{Biografiese kanttekeninge as proloog}

Andries Breytenbach is op 06 Junie 1944 op Bethal gebore. Hy word in 'n gesin van vyf seuns op 'n plaas in die Oos-Transvaalse hoëveld groot. Hy gaan op Bethal skool en studeer vanaf 1963 aan die Universiteit van Pretoria waar hy die grade BA, BA (Hons.) en BD almal met lof verwerf. In 1979 verwerf hy sy DD.

In 1967 is hy met Christa Müller getroud.

Vanaf 1968 doseer hy Hebreeus en Arabies in die Fakulteit Lettere en Wysbegeerte aan die UP, aanvanklik deeltyds maar vanaf 1971 voltyds. In 1974 skuif hy oor na die Fakulteit Teologie (Afdeling A) en doseer Bybelkunde tot 1979 waarna hy medeprofessor word in die Departement Ou-Testamentiese Wetenskap. Hy word in 1992 professor en hoof van die departement. By die departement was hy die studieleier van verskeie doktorale studente. Dit is met trots en verwondering wat ek kan ek getuig van die voorreg om hom as Doctorvater te kon hê.

Sedert 1971 het 36 gekeurde artikels in wetenskaplike vaktydskrifte en boeke uit sy pen verskyn en ongeveer 40 populêr-wetenskaplike artikels, asook 'n boekie getitel Klein Kroniek (1994). Hy het ook verskeie nasionale en internasionale vakwetenskaplike kongresse bygewoon. Met die eenwording van die twee teologiese fakulteite van die Nederduits Gereformeerde en Hervormde Kerke word hy as adjunkdekaan aangestel.

Hy bly in dié pos totdat hy in Maart 2004 uittree om hom voltyds aan die vertaling van die Ou Testament in isiNdebele te wy, die enigste van die elf amptelike tale wat op daardie stadium nog nie oor ' $n$ volledige Bybel beskik het nie. Die projek om die Ou Testament uit die grondtale te vertaal en die bestaande Nuwe Testament grondig te hersien, is aan die einde van 2011 voltooi en die volledige Bybel is op 23 November 2012 bekendgestel.

Sy ervaring in Bybelvertaling dateer terug na die sewentigerjare toe hy die grondvertaling vir die boeke Levitikus en Hosea vir die 1983 Afrikaanse vertaling gedoen het. Hy is tans eksegeet en intravertaler en dien ook op die Redaksionele Kommitee (Ou Testament) van die vertaalprojek Die Bybel: ' $n$ Direkte vertaling van die Bybelgenootskap van Suider-Afrika, wat hopelik in 2017 sal verskyn. In daardie jaar sal die Fakulteit Teologie aan die Universiteit van Pretoria ook 'n honderd jaar oud wees. Andries Breytenbach is ook deur die Bybelgenootskap gevra om die Afrikaanse vertaling van die Ou Testament se tekste vir die redaksionele komitee gereed te kry.

How to cite this article: Geyser-Fouché, A.B., 2013, 'Jotas en tittels het betekenis - die krities-eksegetiese en teologiese bydrae van Andries Breytenbach as Bybelvertaler', HTS Teologiese Studies/Theological Studies 69(1), Art. \#1982, 6 pages. http://dx.doi.org/10.4102/ hts.v69i1.1982

Copyright: @ 2013. The Authors. Licensee: AOSIS OpenJournals. This work is licensed under the Creative Commons Attribution License. 
Hy was vier jaar lank predikant van die Hervormde gemeente Elandspoort in Danville en was daarna deeltyds by die gemeentes Pretoria-Suid en Bronkhorstspruit betrokke.

Hy en sy vrou het vier kinders en drie kleinkinders. Sy groot liefde naas Bybelvertaling was nog altyd boerdery. Die egpaar het hulle in Desember 2011 permanent gevestig op hulle plaas in die Colesberg-distrik waar sy vrou 'n gastehuis bedryf.

In die HTS Teologiese Studies/Theological Studies van 2004 (Buitendag 2004:659), wat aan hom opgedra is, sê die dekaan, prof. Johan Buitendag, dat Andries Breytenbach 'n uiters veelsydige persoon is, met veral twee kenmerke, te wete sy intellek en sy vertelvaardigheid. Praat ' $n$ mens met sy ander oudkollegas, mede-Bybelvertalers en oudstudente is dit duidelik dat hierdie twee kenmerke Breytenbach nog altyd onderskei het.

Sy besondere vaardigheid in Hebreeus besorg hom 'n bepaalde soliede statuur en teenwoordigheid. Hierdie statuur is gewortel in sy worsteling met die Hebreeuse teks. Hy gaan altyd terug na die teks om van daaruit te redeneer en te argumenteer. Menige student en kollega sal erken dat sy teksvermoë hom van ander onderskei en dat dit sommiges dalk selfs effens huiwerig maak om met hom oor die $\mathrm{Ou}$ Testament in gesprek te tree. Tog is dit hierdie selfde kennis wat maak dat ' $n$ mens nie genoeg na hom kan luister nie. In my gesprekke met oudkollegas en mede-Bybelvertalers kom daar elke keer een ding na vore - sy ongelooflike kennis van die Hebreeus en sy knap hantering van die teks. Hy begin nie by sekondêre bronne se opinies oor die teks nie, maar by die teks self.

Dit is hierdie kennis, ervaring en omgang met die Hebreeuse teks wat by hom 'n ontsettende besef geskep het van die groot verantwoordelikheid wat Bybelvertaling behels. Dit is hierdie verantwoordelikheid wat hom noop om in die vertaalproses elke woord te weeg, te oordink, te beproef en meer as een keer te verander totdat hy seker is dat dit wat hy vertaal het, die betroubaarste ekwivalent van die grondtaal is en 'n betekenis oordra wat die oorspronklike teks so getrou moontlik nasê. Meer as een keer het ek hom persoonlik hoor sê dat die vertaling ' $n$ ontsettende verantwoordelikheid is. Sy perfeksionistiese geaardheid sorg daarvoor dat hy nooit kan bes gee voordat die teks so na as moontlik aan perfek vertaal is nie.

In die gemelde HTS Teologiese Studies/Theological Studies huldigingsbundel skryf Theuns Dreyer (2004:666) dat Breytenbach altyd probeer het om die Woord van God vir vandag vars en nuut te sê. Daardie omskrywings van die Psalms in die Liedboek wat sy brein- en pennevrug was, is 'n voorbeeld van sy kreatiewe omgang met taal. Dit bevestig sy vermoë om vanuit die Hebreeus die Bybel in teks en lied in Afrikaans te laat praat en sing. Sonder om die inhoud van die Hebreeuse teks te verloor, kry hy dit reg om ook in Afrikaans poëties te skryf - 'n talent wat van hom 'n uitsonderlike woordkunstenaar maak. 'n Deel daarvan sien ons in sy liefde vir storievertel. Hy was ook 'n huisvriend van oorlede Jan Spies en het 'n reeks 'Klein Kronieke', wat later in boekformaat uitgegee is, vir die Konteks geskryf. Ek onthou nog dat lesers nie kon wag dat die volgende maand se uitgawe verskyn nie. Dit, asook sy huidige studie in Kreatiewe Skryfkuns, is ' $n$ bewys van sy passie en liefde vir taal.

\section{Teologiese vorming}

In sy voorgraadse studie is Breytenbach sterk deur W.C. van Wyk (sr.) en A. van Selms beïnvloed. By Van Wyk het hy nie net die liefde vir Hebreeus geleer nie, maar ook dat tekste noukeurig gelees moet word. Hy het geleer dat die jotas en tittels betekenis het en dat dit aan die boodskap van die teks 'n groot verskil kan maak. By Van Selms het hy geleer dat tekste tuis is in 'n leefwêreld en dat die leefwêreld wat die leser meestal onwillekeurig rekonstrueer 'n beslissende rol speel by die verstaan van die teks. In sy nagraadse studie in Semitiese tale het die teologie van Van Selms en die wyse waarop hy tekste uit die Ou Nabye Ooste gelees het sy denke verder help vorm.

In sy BD-studie het die godsdiensfilosoof F.J. van Zyl die belangrikste rol in die vorming van 'n dialekties-kritiese teologiese basis by Breytenbach gespeel. Hy is veral beïnvloed deur die werk van Emil Brunner, Wahrheit als Begegnung, wat deur Van Zyl voorgeskryf is. Van Zyl se lesings het sy siening oor die kerk en die plek van die kerk in die wêreld help vorm. Dit was dan ook Van Selms en Van Zyl wat op Breytenbach invloed uitgeoefen het. Nederlandse Ou-Testamentici soos J.J.P. Valeton (1848-1912) het nie net 'n stempel op persone soos Gemser en Van Selms afgedruk nie, maar deur Gemser, Van Selms, Van Wyk (sr.) en Oberholzer ook op 'n jonger geslag soos Breytenbach. Die teologie van Gemser en Van Selms is in Nederland deur onder andere Valeton beïnvloed (Loader 1985:233). Valeton het die histories-kritiese eksegetiese benadering van voorgangers in die Ou-Testament soos Graf, Kuenen en Wellhausen verinnerlik. Meer nog, hy het nooit die rol wat geloof in die ethos (in Grieks) of lewenswyse van 'n eksegeet speel uit die oog verloor nie.

Hierdie integriteit tussen gelowig wees en kritiese eksegese kan in die eerste plek gesien word in die passievolle betrokkenheid by aktiewe kerklike meelewing, prediking en pastorale deelname op gemeentelike en amptelike vlakke. In die tweede plek mond hierdie integriteit uit in 'n kritiese solidariteit in die uitleg en toepassing van die ekumeniese en Reformatoriese belydenisskrifte. Derdens inhibeer so 'n integriteit nie die profetiese en kritiese stem téén die kerk en kerklike besluite waar dit nodig is nie. Daar is ook 'n vierde gevolg van so 'n krities-integrale wetenskaps- en geloofsbenadering, naamlik die onuitblusbare passie om die Bybel vir iedereen in vertaling toeganklik te maak - en dit sluit mense van ander kultuurgroepe as die eie in.

Venter (2004:) som dit soos volg op:

Andries Breytenbach ... followed Jeismann (1985:13-14) in his view that history writing always has an 'identitätstiftende Funktion', 'Legitiemierungsfunktion', and an 'Orientierungsfunktion'. 
Breytenbach applied these principles of indentity forming, legitimating and orientation to the process of canonisation. He saw it as a process which took place in the context of 'historical consciousness, the contextuality and intertextuality of texts, master narratives and contra narratives and the community of interest' in forming a canon. (bl. 703)

Le Roux (1993) verwys na Breytenbach se navorsing oor Hosea en beskryf sy metode en benadering soos volg:

Breytenbach's sketch was the result of thorough exegesis. And to him this implied a text immanent approach. Put differently: the text was approached sinchronically [en dan haal hy Breytenbach aan] 'aangesien dit [menende sinkroniese aanslag] die beste waarborg is dat willekeur so ver moontlik uitgeskakel word by die uitleg.' (bl. 233)

Le Roux (1993) sê dat Breytenbach die insigte van die Duitse Ou-Testamentikus Wolfgang Richter in 'n vereenvoudigde vorm toegepas het sodat die volgende bekende stappe gevolg is:

the demarcation of a pericope, the treatment of text critical problems, the determination of the form, et cetera. Of special importance was the analysis of the structure. Diachronical information also served some purpose but took subordinate position. (bl. 233)

\section{Skrifbeskouing}

Breytenbach se skrifbeskouing spruit onder andere uit sy intense omgang met die Hebreeuse teks van die Ou Testament. Sy bestudering van die boek Hosea onder die leiding van J.P. Oberholzer en sy deelname aan die Afrikaanse vertaling van die Bybel wat in 1983 gepubliseer is, ${ }^{1}$ het hom verplig om die bronteks uiters noukeurig te bestudeer. Dit geld ook vir sy uitgebreide verklarende aantekeninge by die boek Levitikus wat in die Verklarende Bybel² verskyn het.

Hierdie navorsing het by hom die oortuiging dat die Bybel nie ' $n$ foutlose geskrif is nie, verder versterk. Daarmee saam het basiese insigte uit die literatuurwetenskap ook by hom 'n rol gespeel. So byvoorbeeld het die insig dat ' $n$ woord nie ' $n$ betekenis het nie, maar betekenismoontlikhede wat deur die verband waarin dit staan, vernou en ook beslissend bepaal word, by hom die oortuiging gevestig dat ' $n$ woordvir-woord vertaling van die Ou Testament uit Hebreeus nie net onhoudbaar is nie, maar inderdaad ook tot misverstand kan lei. Die aanhaal van woorde buite die verband waarin dit staan, lei byna sonder uitsondering tot die skep van nuwe inhoud vir daardie woorde.

Hierdie insigte het ook 'n beslissende rol gespeel in sy beskouing oor die verhouding tussen die Ou- en die Nuwe Testament. Dit het vir hom duidelik geword dat die aanhaal van woorde buite konteks asook die gebruik van tipologie en allegorie tipiese Joodse wyses van Skrifuitleg in die tyd van die Nuwe Testament was. Die skrywers van die Nuwe Testament het die Ou-Testamentiese geskrifte op hierdie selfde wyse gebruik om hulle lesers, wie se Heilige Skrif die Septuaginta was - die Griekse vertaling van die Ou 1.Breytenbach het Hosea en Levitikus 8 tot 27 vertaal.

2.Verklarende Bybel (1983-vertaling), 1989, Lux Verbi, Kaapstad.
Testament - te oortuig dat Jesus van Nasaret die verwagte Messias is. Hierdie standpunt van Breytenbach is in enkele kerklike publikasies verwoord. Hy het dieselfde standpunt gehandhaaf in die radioprogram Wat sê die Bybel, waaraan hy ' $n$ tyd lank deelgeneem het. Dit het ook meegebring dat hy kritiek uitgespreek het teen die sogenaamde beloftevervulling skema waarmee sommige teoloë die verhouding tussen die twee Testamente probeer verklaar. Sy oortuiging is dat, as die Ou Testament bloot beloftes is oor die koms van Christus na die wêreld - beloftes wat in die Nuwe Testament volledig vervul is - die Ou Testament geen waarde meer vir Christene het nie. Want waarom nog 'n belofte lees as dit reeds vervul is? Ook die sogenaamde 'dieper betekenis' van die Ou Testament is om dieselfde rede deur hom bevraagteken: Waarom nog geskrifte lees waarin Christus op 'n verborge wyse teenwoordig is, as die Nuwe Testament helder en duidelik getuig oor hierdie Seun van God. In verdere kritiek van Breytenbach teen die tradisionele siening oor die verhouding Ou- en Nuwe Testament wys hy daarop dat die Heilige Skrif van die Nuwe-Testamentiese skrywers die Septuaginta was wat op talle plekke (en in die boek Jeremia radikaal) verskil van die Joodse kanon wat die basis van die eerste Protestantse Bybelvertalings was. Dit alleen maak al 'n meganiese Skrifbeskouing totaal onaanvaarbaar.

Hierdie standpunte van Breytenbach het hom natuurlik uit sommige kringe kritiek op die hals gehaal. Daarteenoor het hy sy siening verdedig wat kortliks op die volgende neerkom: Die Ou Testament is ' $n$ geskiedenis van God se bemoeienis met Israel en die wêreld. In hierdie geskiedenis tree God met mense in verhouding. Hy bly getrou aan sy ondernemings teenoor hulle, maar die verhouding word telkens deur die ontrou van mense geskaad. Dit bring mee dat van die profete begin uitsien na ' $n$ tyd in die toekoms waarin God die verantwoordelikheid vir die handhawing van hierdie verhouding op Homself sal neem. God doen dit dan deur sy Seun na die wêreld te stuur. Anders as wat in die $\mathrm{Ou}$ Testament verwag word, is die Messias nie 'n aardse koning soos Dawid nie, is daar nie twee messiasse nie (vergelyk Sag $4: 14 ; 6: 13$ ) en strek die ryk van hierdie Messias baie wyer as Israel. In Christus het God dus baie meer gegee as wat in die Ou Testament as verwagting uitgedruk is.

In die algemeen kan dus gesê word dat Breytenbach, wat Skrifbeskouing betref, hom tuis voel by 'n standpunt soos die verteenwoordigers van die Hervormde Kerk op die destydse Tussenkerklike Kommissie dit teenoor Gereformeerdes verwoord het: Die waarheid van die Skrif is nie bloot 'n optelsom van enersyds objektiewe geloofsproposisies en andersyds 'n optelsom van subjektiewe geloofservarings wat in óf die Bybel self óf in die teologiese tradisie aangetref word nie (vgl. Breytenbach 1995:702 en kyk ook na Baarda et al. 1981).

Breytenbach se 'waarheidsbegrippe' kan in sy verstaan van die 'kerkbegrip' gesien word. Breytenbach (1995) beklemtoon dat:

... $[t]$ eologiese nadenke vanuit die Ou-Testament ... gedoen [behoort te] word binne [1] die breë kontoere wat die kritiese navorsingsresultate aangedui het; [2] gerig [behoort te] wees op 
die breë teologiese inhoud van ' $n$ bepaalde boek of korpus uit die Ou-Testament; en [3] die historiese bedding van hierdie teologiese inhoud deeglik in ag [te] neem. (bl. 703)

Breytenbach se 'kerkbegrip' laat geen ruimte vir ideologiese groepvorming binne die kerk nie. Nie net was hy die eerste ampsdraer van die Hervormde kerk wat met 'n formele voorstel op ' $n$ Algemene Kerkvergadering teen die ideologiese stem en blokvorming van die HCM Fourie Stigting beswaar gemaak het nie, maar sy verstaan van wat 'kerk' is, bied ook geen ruimte vir modaliteitsvorming nie. Op grond van Bybelse getuienis sê Breytenbach (1995):

Omdat daar één God is, is daar wesenlik één geloofsgemeenskap. Hierdie wesenlike eenheid moet oor alle grense van politieke en staatkundige verdeeldheid heen gehandhaaf word. Die vraag hóé dit gedoen moet word, sal in die lig van gegewens uit die Nuwe Testament beantwoord word. (bl. 710)

Wat Skrifinspirasie betref, vind hy aansluiting by die standpunt van Karl Barth dat die Skrif nie die Woord van God is nie, maar deur die werk van die Heilige Gees die Woord van God word. Hy grond sy afwysing van die tradisionele meganiese Skrifbeskouing, dat die Skrif woordvir-woord deur die Heilige Gees geïnspireer is, onder andere op die feit dat die 'hele Skrif' waarvan daar in 2 Timoteus 3:16 sprake is, verwys na die Septuaginta, wat verskil van die Joodse kanon. Verder sê die betrokke vers ook duidelik wat inspirasie beteken, naamlik dat dit 'groot waarde [het] om in die waarheid te onderrig, dwaling te bestry, verkeerdhede reg te stel en 'n regte lewenswyse te kweek.'

Hierdie uitgangspunte van Breytenbach het dit vir hom moontlik gemaak om kritiese teologie te beoefen sonder om sy solidariteit met die kerk prys te gee. Hy is oortuig daarvan dat die Bybel tans ' $n$ groter plek in sy lewe inneem as wanneer hy dogmatisties oor die Bybel sou praat of bloot sou nasê wat die kerk in amptelike vergaderings oor die Bybel sê. Sy besluit om op 'n stadium 'n gevestigde akademiese loopbaan prys te gee en hom voltyds aan die vertaling van die Ou Testament en later ook die hersiening van die Nuwe Testament in isiNdebele te wy, spruit ook uit die belangrike plek wat die Bybel in sy lewe inneem.

Sy bestudering van ongevokaliseerde tekste uit die Samaritaanse liturgiese tradisie het ook vir hom 'n nuwe visie op bepaalde aspekte van die Nuwe-Testamentiese wêreld en teologiese oortuigings gegee. Dit het weereens aan hom bevestig dat daar verskillende tradisies in 'n verskeidenheid Masoretiese tekste ter sprake is.

Breytenbach neem die Protestantse slagspreuk sola Scriptura ernstig op. In sy bestudering van die Bybel laat hy hom nie voorskryf deur een of ander verstaansleutel of dogmatiese proposisie waarmee die Skrif gelees moet word nie. Dit geld ook die drie belydenisskrifte wat hy waardeer as goeie teologiese geskrifte wat vir hulle eie tyd antwoorde moes gee op die stryd waarin gelowiges gewikkel was, maar wat nie ongekwalifiseerd vandag as sleutel vir die verstaan van die Bybel kan geld nie (kyk na sy artikel: Belydenisvorming as kanonisering van geloofsoortuigings in die verband; Breytenbach 2000). In sy eksegese probeer hy met alles in sy vermoë hoor wat die Hebreeuse of Griekse woorde sê binne die literêre verband waarin dit staan, maar ook wat dit waarskynlik gesê het binne die leefwêreld waarin dit vir die eerste keer gehoor is. Hy skroom nie om weersprekings, historiese onjuisthede en ander gebreke in die boeke van die Bybel uit te wys nie. Dit verhinder hom egter nie om die Protestantse kanon steeds as die onvervangbare bron vir geloof in die lewende God te aanvaar nie.

Breytenbach (2000) verwoord sy siening van geloof soos volg:

Geloof is nie 'n religieuse securitas nie, maar die certitudo van 'n diepe afhanklikheid van 'n onsienlike God. Dit is 'n vaste oortuiging oor dit wat nie gesien nie, maar gehoop word. Kritiek op die kanonisering van geloofsoortuigings beteken nie dat alles gerelativeer word nie. Die Bybel met sy uiteenlopende en selfs teenoorstaande perspektiewe op die verhouding tussen God en mens, bly binne die Protestantse tradisie die enigste basisteks vir teologisering en vir geloof in ons eie tyd. Juis die diversiteit van hierdie basisteks profileer die geloof in God: Geloof is nie 'n gearriveerdheid nie maar ' $n$ konstante soek en vind. Soos Luther gesê het: Dis waar, ons bly bedelaars voor God. Geloof is minder kennis en meer vertroue. Dit is nie 'n skolastiese verklaring van alles nie, maar die erkenning dat ons baie nie weet nie. Hierdie nie-weet maak ruimte vir die verwondering as 'n wesenlike element van geloof. Dieselfde pleidooi vir 'n geloof wat in verwondering kan swyg, word al in die boek Job gelewer: Die vriende van Job wat alles kon verklaar in netjiese teologiese taal, word afgewys en Job, die kritiese opstandeling wat in verwondering tot swye gebring word, word gevindikeer (Job 47:7v). (bl. 388)

\section{Teologie}

Op die vraag na die kerk se teologie, het Breytenbach geantwoord dat enige vraag na die teologie in groot beskeidenheid beantwoord moet word:

... [Dit] is (dit) duidelik dat ' $n$ mens maar beskeie moet wees by die beskrywing van die Kerk se teologie. Dit kan trouens niks meer wees as ' $n$ weergawe van hoe 'n mens self subjektief die teologiese gesprek wat in die Kerk gevoer is en gevoer word, verneem nie. Die teologie van die Kerk is inderdaad niks anders as ' $n$ gesprek nie - 'n gesprek waarin elkeen wat daaraan deelneem, uitsprake maak oor God in sy verhouding met mense en oor mense in hulle verhouding met mekaar op grond van die verhouding met God. Wie goed luister na so 'n gesprek, kan bepaalde tendense aandui, kan sê vanuit watter agtergrond en in watter rigting 'n teoloog of groep teoloë praat. Wat wel opvallend is, is dat die Nederduitsch Hervormde Kerk selde indien ooit net uit een mond gepraat het as dit by die teologiese gesprek kom. Dit sou ook verdag wees indien die Kerk net uit een mond gepraat het, want dit is een van die kenmerke van 'n ideologie, maar nie van teologie nie. Dit was van die begin af eie aan die aard van menslike spreke oor en van God dat daar diversiteit, verskillende beklemtonings en verskillende blikrigtings is. Die Ou Testament met sy verskillende teologieë en die Nuwe Testament met sy verskillende teologieë bied oorvloedige getuienis daarvan. Die ideaal van een teologie vir 
die kerk is nie net onrealisties en onhaalbaar nie, dit is ook onBybels. Een gesistematiseerde en sluitende teologiese sisteem sou as 'n soort meesterkode die teologiese gesprek, en daarmee die teologie, tot ' $n$ einde bring... [Die bedoeling is] om die gesprek oop te hou. Anders gesê: om die teologie lewend, beskeie en daarom relevant te probeer hou. (Van Wyk 1999:172)

Uit die voorafgaande is dit reeds duidelik dat Breytenbach hom by die breë stroom van dialektiese en krities-gelowige teoloë tuis voel. Die dialekties teologie verwoord Breytenbach soos volg:

Die dialektiese teologie is deur HP Wolmarans in die Nederduitsch Hervormde Kerk bekend gestel. Dit word ook algemeen aanvaar dat FJ van Zyl, as 'n kenner van Barth, later 'n groot rol gespeel het in die vestiging van 'n dialektiese benadering in die Nederduitsch Hervormde Kerk. Die dialektiese teologie het in verskillende opsigte 'n antwoord gebied op die vrae-kompleks van die historiese kritiek en die rasionalisme. Naas die eie aard van 'n dialektiese benadering wat die waarheid nie in enkelproposisies uitgedruk sien nie, maar in 'n geloofsverhouding met God, het die beskouing oor God as die Gans Andere direk ingegaan teen die waarheidsbeskouing van die rasionalisme. Daarby het die verklaring van die menslikheid en goddelikheid van die Bybel na analogie van die mensheid en Godheid van Jesus Christus, sowel as die stelling dat die Bybel nie God se Woord is nie, maar deur die werk van die Heilige Gees God se Woord word, antwoorde gebied op die foute en teenstrydighede in die Bybel wat deur die historiese kritiek onder die vergrootglas geplaas is. 'n Groot groep van die Kerk se predikante het vanaf die vyftiger en sestiger jare deur kennismaking met die dialektiese teologie van Brunner en Barth (in die lesings van HP Wolmarans en FJ van Zyl) en later Van Niftrik (in die lesings van BJ Engelbrecht) geleer om dialekties te dink en so aan geloof en rede ruimte te gee in hulle teologiebeoefening. (Van Wyk 1999:175)

Aan die hand van Ebenhard Bethge (1995) se versameling van Dietrich Bonhoeffer se werke beskryf Breytenbach sy verstaan oor wat die kerk se taak ten opsigte van 'kultuur' is (Breytenbach 2005:874-880). Hy is krities teenoor die Calvinisme wat 'teokrasie' as ideologie inspan. Hy meen dat die biologiese rol van Israel in 'n verbonds- of volkskerk onherroeplik verby is. Die lidmaat van die kerk het ' $n$ 'burgerlike' plig net soos ander lede van 'n kultuurgroep wat nie deel van die kerk is nie. Die kerk het net een taak - om die evangelie van Jesus Christus te verkondig. Daarom moet die kerk altyd self-krities wees, en vanuit só 'n houding van nederigheid is die kerk 'n getuie in die wêreld, bid die kerk vir die wêreld en is die kerk gevul met deernis vir die wêreld.

Volgens sy eie getuienis het hy as kind ook die algemeen geldende idealisering van die Afrikaner gedeel. Sy eerste ontnugtering met 'die Afrikaner' en veral met voornemende predikante van die kerk was in die universiteitkoshuis waar daar ' $n$ hele aantal teologiese studente tuis was. Hierdie ontnugtering is later deur die knoeiery van kollegas voor en tydens Algemene Kerkvergaderings vergroot. Dit het daartoe gelei dat hy nie net oor 'die Afrikaner' nie, maar ook oor leiers in die kerk begin sinies raak het. Bonhoeffer se geskrifte het hom van sy sinisme bevry en hom met ander oë na die gebroke wêreld, wat 'die kerk' genoem word, laat kyk. Daarom het hy by geleentheid van die ontvangs van die HCM Fourie erepenning Bonhoeffer in vertaalde vorm aangehaal:

Nêrens in die wêreld word God se Naam so ydelik gebruik, word die gebooie van God so oortree, word die opdrag van Christus om mekaar lief te hê so verontagsaam, word Hy so verloën en verraai as juis in die kerk nie. Nêrens anders in die wêreld vind 'n mens soveel skynheiligheid en skynvroomheid as juis in die kerk nie. Maar nêrens anders in die wêreld vind 'n mens hulle wat deur God geroep is tot die ewige lewe nie, as juis in die kerk. (Nederduitsch Hervormde Kerk van Afrika [NHKA] 2004:22)

Bonhoeffer het hom gehelp om aan die slagspreuk sola gratia 'n groter plek te gee in sy nadenke oor wie en wat die kerk is.

Breytenbach was een van die eerste Ou-Testamentici in Suid-Afrika wat in die negentigerjare godsdiensfilosofiese tendense van die vorige eeu ook op sy studie van die $\mathrm{Ou}$ Testament van toepassing gemaak het. In een van sy werke wat die meeste aangehaal word, ' $[m]$ eesternarratiewe, kontranarratiewe en kanonisering - 'n perspektief op sommige profetiese geskrifte' (Breytenbach 1997b), waarin hy die insigte van die Franse filosoof Jean-François Lyotard verwerk het, beskryf hy op meesterlike wyse die teologiese kontroversie in profetiese getuienisse in onderskeidelik Noord- en Suid Israel. Dominante meesternarratiewe verwoord maghebbers se tekste, soos byvoorbeeld die Judese oorheersing van Samaritaanse sentimente in Noord-Israel.

Van Aarde (2001) verwys soos volg na insigte wat uit hierdie meesterlike artikel van Breytenbach voortgekom het:

[Round] about the middle of the eight-century B.C.E., the dominant belief in Israel was that Israel was God's covenanted people and that the cultic shrine at Bethel was the visible guarantee that Israel would continue to exist as kingdom (see inter alia Amos 7:10-13). Among the evidence in the Pentateuch [traditions], Deuteronomy 33:13-17; Genesis 37:1-11 and Genesis 49:26 witness to the belief that Joseph was the legitimate successor of his father Jacob and not Judah. According to this tradition, the cultic site to which God's people were attached was Bethel, also called Luz (Gen 28:19; 35:6). At Bethel, heaven and earth met as God entered into a covenant with Jacob and Jacob's children. Here, on the road between Bethel and Bethlehem (Ephrath), Rachel died and was buried (Gen 35:19). At the time of the centralization of the cult in Jerusalem, earnest attempts were made to disfavor and even to destroy the Bethel tradition (see, e.g., Hos 4:15 were the expression Beth Aven serves as a caconym [word with a bad referential meaning] for Bethel; Hos 10:5; Am $5: 5 ; 8: 14)$. The prophet Hosea (1:4-5), for example announced that the vengeance of God would be wreaked against the Northern Kingdom Israel because of the massacre of Judeans in the Valley of Jezreel by Jehu, the king of the Northern Kingdom (see Kings 9:1-10:28). According to Hosea, the termination of the covenant entered into at Bethel would be the punishment of God. (bl. 85)

Hierdie bevindings van Breytenbach vind veral neerslag in sy artikel 'Die Herfsfees en die Koningsrite by Bet-El as Interteks van Amos 7:10-8:14 en Hosea 9:1-9' (Breytenbach 1997a) asook die artikel getiteld: '"Seun van Josef" uit 'n Noord-Israelitiese Perspektief' (Breytenbach 1998).

Breytenbach is nie op 'n eenduidige en rigiede wyse aan 'n bepaalde teologiese tradisie in die Bybel en na-Bybelse kerk 
verknoop nie. As dit gaan oor die Ou Testament voel hy byvoorbeeld meer aangetrokke tot die teologiese oortuigings wat in die Samuel- en Koningsboeke neerslag gevind het as tot dié in die Kronistiese geskiedswerk. Hy lees laasgenoemde as 'n hervertelling van die oorgelewerde geskiedenis deur die Jerusalemse elite wat daarmee onder andere hulle aansprake op en beheer oor die sentrale godsdienstige instelling, naamlik die tempel, wou versterk. As dit gaan oor die Reformasie voel hy hom meer tuis by Luther as by Calvyn, veral omdat laasgenoemde so sterk sistematiserend gewerk het en daar (volgens Breytenbach) 'n sterk skolastiese inslag by Calvyn is. Hy wys daarop dat die histories-kritiese navorsing dit onmoontlik gemaak het om die Ou Testament soos Calyn te verstaan:

It is clear to me that theologians in the post-critical era can no longer maintain Calvin's hermeneutic points of departure, his manner of theologising and that of his followers. Reading the Old Testament as a timeless scripture with an unambiguous prescriptive message means that the questions and problems tabled during the past two centuries of dedicated study of the Old Testament are simply ignored. Development in the field of Old Testament studies in the past two centuries and the irrefutable results produced by research, make it unthinkable that the Old Testament could still be used with a 'first naiveté' in a theological debate. (Breytenbach 2005:873)

As iemand hom vandag sou vra na sy kennis oor God, sou hy antwoord:

Hoe ouer ek word, hoe minder weet ek van God, hoe minder verstaan ek sy weë. En soos my sekerhede oor Hom afneem, so neem my dankbaarheid teenoor Hom toe. Dit is in die laaste tyd vir my belangriker om my te verwonder as wat dit is om te weet. (NHKA 2004:23)

Hiermee sê hy dat hy dankbaar is dat hy God volledig mag vertrou en dat sy lewe om Christus ontwil geborge is by God. Hy sê dat sy 'teologie' eintlik maar net 'n sola fidei is wat deur sola scriptura gevoed word.

Wie Andries Breytenbach is, is baie goed deur Theuns Dreyer in 2004 se huldigingsbundel van HTS aan Breytenbach opgesom:

Sy skerp intellek, teologiese insig en integriteit as 'n gelowige het ons almal verryk. As Bybelwetenskaplike het hy met erns en deeglikheid tekste bestudeer, as Bybelvertaler het hy dit in eietydse taal onder woorde gebring, as prediker het hy dit met oortuiging verkondig en as gelowige het hy dit uitgeleef. (Dreyer 2004:665-666)

\section{Erkenning Mededingende belange}

Die outeur verklaar dat sy geen finansiële of persoonlike verbintenis het met enige party wat haar nadelig kon beïnvloed in die skryf van hierdie artikel.

\section{Literatuurverwysings}

Baarda, T.J., Firet, J., Den Heyer, C.J., De Moor, J.C., Van Peursen, C.A., Veenhof, J., Vlaardingerbroek, J. \& Weiland, H.B., 1981, God met ons: ...over de aard van het Schriftgezag, Tijl-Libertos, Utrecht.

Bethge, E., 1995, Friendship and resistance: Essays on Dietrich Bonhoeffer, World Council of Churches, Geneva.

Breytenbach, A.P.B., 1994, Klein kroniek: Oorloopstories van 'n verlede, Kital, Pretoria.

Breytenbach, A.P.B., 1995, 'Nadenke oor die kerkbegrip: Enkele perspektiewe op grond van die Deuteronomistiese geskiedenis', HTS Teologiese Studies/Theological Studies 51(3), 702-71. http://dx.doi.org/10.4102/hts.v51i3.1425

Breytenbach, A.P.B., 1997a, 'Die Herfsfees en die Koningsrite by Bet-El as interteks van Amos 7:10-8:14 en Hosea 9:1-9', HTS Teologiese Studies/Theological Studies 53(3), 513-528. http://dx.doi.org/10.4102/hts.v53i3.1659

Breytenbach, A.P.B., 1997b, 'Meesternarratiewe, kontranarratiewe en kanonisering: 'n Perspektief op sommige profetiese geskrifte', HTS Teologiese Studies 53(4), 1161-1186. http://dx.doi.org/10.4102/hts.v53i4.1774

Breytenbach, A.P.B., 1998, "'Seun van Josef” uit 'n Noord-Israelitiese perspektief', Old Testament Essays 11(3), 415-426.

Breytenbach, A.P.B., 2000, 'Belydenisvorming as kanonisering van geloofsoortuigings', HTS Teologiese Studies/Theological Studies 56(2/3), 377-390.

Breytenbach, A.P.B., 2005, 'The church's responsibility towards the social order: An Old Testament hermeneutic problem', HTS Teologiese Studies/Theological Studies 61(3), 861-881. http://dx.doi.org/10.4102/hts.v61i3.467

Buitendag, J., 2004, 'APB Breytenbach: Huldigingswoord en Curriculum Vitae', HTS Teologiese Studies /Theological Studies 60(3), 659-664.

Dreyer, T.F.J., 2004, 'God die Allerhoogste, woon nie in mensgemaakte konstruksies nie', HTS Teologiese Studies/Theological Studies 60(3), 665-672. http://dx.doi. org/10.4102/hts.v60i3.778

Le Roux, J.H., 1993, 'A story of two ways: Thirty years of Old Testament scholarship in South Africa', Old Testament Essays, suppl. ser. 2.

Loader, J.A., 1985, 'JJP Valeton jr as godsdienshistorikus', HTS Teologiese Studies/ Theological Studies 41(2), 233-251.

Van Aarde, A.G., 2001, Fatherless in Galilee: Jesus as Child of God, Trinity Press International, Harrisburg.

Van Wyk, D.J.C. (red.), 1999, 20ste eeu Hervormde teologie, SENTIK, Pretoria.

Venter, P.M., 2004, 'Reviewing history in apocalyptic literature as ideological strategy', HTS Teologiese Studies/Theological Studies 60(3), 703-723. http://dx.doi. org/10.4102/hts.v60i3.574

Nederduitsch Hervormde Kerk van Afrika (NHKA), 2004, 'Notule van die 67ste Algemene Kerkvergadering van die Nederduitsch Hervormde Kerk van Afrika', Argief van die Nederduitsch Hervormde Kerk, Pretoria. 